\title{
Modulation of mood states as a major factor in relapse to substance use
}

\author{
Gal Yadid ${ }^{1,2 *}$, Lior Redlus ${ }^{1}$, Royi Barnea ${ }^{1,2}$ and Ravid Doron ${ }^{3,4}$ \\ 1 The Neuropsychopharmacology Lab, The Leslie and Susan Gonda (Goldschmied) Multidisciplinary Brain Research Center, Bar-Ilan University, Ramat Gan, Israel \\ 2 The Neuropsychopharmacology Lab, The Mina and Everard Goodman Faculty of Life Sciences, Bar-llan University, Ramat Gan, Israel \\ ${ }^{3}$ Department of Education and Psychology, The Open University, Ra'anana, Israel \\ ${ }_{4}$ School of Health and Life Sciences, Hadassah Academic College, Jerusalem, Israel \\ ${ }^{*}$ Correspondence: yadidg@gmail.com \\ Edited by: \\ Ildikó Rácz, University of Bonn, Germany
}

Substance dependence is characterized by compulsive substance seeking and high vulnerability to relapse. A major challenge in current substance addiction research is not only to understand the immediate effects of substances of abuse on brain operations. It is also to define, at the behavioral and neural levels, how cognitive, emotional, and motivational processes interact with substance use in order to lead to this psychopathological state which defines addiction. For the last decade, research and progress into the biological basis of the addictive process has led to a rapidly growing number of pharmacological agents used to interrupt the progress of the addiction pattern, however without a significant/adequate impact.

It seems that the abstinent versus satiated states differ significantly (Kalivas and Volkow, 2005). Prolonged abstinence from substances of abuse is characterized by dysphoria, depression, and anxiety, coupled with high stress and craving; therefore strongly affecting the quality of life. It is speculated that memories of habitual substance use, produced by anxious and/or stressful emotional states, may have implications for understanding the role of learning and memory processes in substance addiction (Perrine et al., 2008; Packard, 2009). Substance dependent individuals, during their withdrawal, commonly employ thought-suppression to cope with stress and intrusive cognitions about the substance (Garland et al., 2012). Hence, abstinence-induced stressrelated mood disorders are considered to be the main valence to define addiction as a chronic brain disorder, and stress is one of the major factors in substance seeking and relapse to its usage (Lu et al., 2003; Koob and Zorrilla, 2010).
Understanding the neurobiological basis of the abstinent state is a necessity to adequately treat substance relapse. The development of addiction and vulnerability to relapse following withdrawal is proposed to be the result of neuroadaptive processes within the central nervous system, leading to impairment in the mechanisms that mediate positive reinforcement and the emergence of affective changes (Weiss et al., 2001). A plethora of gene changes develop in the brain during chronic use or abstinence, which are related to the glutamate/ corticoids, CREB/ERK, and NfאB pathways (Nestler, 2005; Li et al., 2008). Regardless the substance, a specific set of genes (Adora2a, Cnr1, Drd1, GPR88, Pde10a, Arpp21, Fam40b, Hpca, and Bc111b; mostly belonging to a huntingtin-centered pathway) were downregulated in the abstinent brain (Kalivas and Volkow, 2005; Le Merrer et al., 2012), hence possibly contribute to the negative affect characterizing protracted abstinence. Not surprisingly, these neuroadaptations, which occur during the addiction process, have been associated with multiple neuropsychiatric disorders (de Lecea et al., 2012).

Chronic stress increases the risk of depression, and is well known to increase relapse to drug seeking behavior (Bruchas et al., 2010). Depressive symptoms were suggested to be associated with abstinence-induced alterations in response to negative distracters (Froeliger et al., 2012). Findings suggest that the severity of depression symptoms are an important predictor of psychosocial treatment efficacy for cocaine dependence and, hence, underline the importance of adequately addressing depression symptoms to improve treatment outcomes (Stulz et al., 2011).
Serotonergic dysregulation in depression and addiction comorbidity was suggested as a novel target for the treatment of addiction and the prevention of drug relapse (Kirby et al., 2011). A few randomized clinical trials support the use of some antidepressant medications for combined cocaine dependence and depression (Rounsaville, 2004). Nonetheless, at the current stage of evidence, data do not unambiguously support the efficacy of antidepressants in the treatment of substance abuse/dependence (Pani et al., 2011). Notably, most negative results came from studies that evaluated selective serotonin reuptake inhibitors (SSRIs), while most positive results were found using norepinephrine/dopamine-reuptake-inhibitors, such as desipramine or bupropion. Although psychiatric symptoms are the prime motive of addicts requesting treatment, they are not always the expression of an associated mental disorder. Indeed, the presence of depressive/anxious symptomatology in the clinical presentation appears to be unnecessarily related to "dual diagnosis" (i.e., addiction and a mental illness). High-frequency abusers demonstrate an associated increased hypothalamic-pituitary-adrenal (HPA) axis activity, a characteristic stress response, to drug-cue exposure (Koob and Zorrilla, 2010). The role of the norepinephrine system in stress is well known, and its involvement in the mechanisms/potentiation of substance abuse has been explored (Belujon and Grace, 2011). Therefore, we suggest that noradrenergic antidepressants are effective in the treatment of substance relapse, since they initially control the stress circuit, and secondarily ease the depressive symptoms.

There is a preponderance of evidence that abuse of substances is parallel with stress disorders (Lu et al., 2003; Koob and 
Zorrilla, 2010; Sinha, 2011; Moeller, 2012), and anxiogenic effects of abstinence from substances of abuse is dependent on the period of the withdrawal. The administration of anxiolytic agents, such as propranolol and buspirone or the 5-HT3 receptor antagonist ondansetron, after an abstinence period, reversed the anxiogenic effect induced by nicotine, alcohol, cocaine, and opiates (Costall and Naylor, 1992; de Oliveira Citó Mdo et al., 2012).

Several neuropeptides, including corticotrophin-releasing hormone, neuropeptide Y, hypocretin/orexin, nociceptin/ orphanin have been shown to be stressrelated. Not surprisingly, they also play a pivotal role in addiction, mediating the negative affect associated with stress (Boutrel and de Lecea, 2008; Bruijnzeel, 2012). Endogenous opioid-neuropeptides, such as $\beta$-endorphin, dynorphin, enkephalin, and others, have been shown to play a major role in substance reinforcement (Tang et al., 2005; Roth-Deri et al., 2008; MerenlenderWagner et al., 2009; Wee and Koob, 2010).

Herein we wish to present a new piece to this puzzle, suggesting two putative candidates: the opioid neuropeptide $\beta$-endorphin and the neurosteroid dehydroepiandrosterone (DHEA), both shown to modulate mood and addiction.

$\beta$-endorphin is an endogenous opioid produced mainly in the arcuate nucleus of the hypothalamus, and released, in part, in the nucleus accumbens (NAc). $\beta$-endorphin induces euphoria and has rewarding and reinforcing properties (Roth-Deri et al., 2008). Consequently, it was demonstrated that cocaine induces dopamine-1-receptor dependent $\beta$-endorphin release in the NAc (Roth-Deri et al., 2008). Moreover, mice lacking $\beta$-endorphin demonstrated attenuation in cocaine-induced conditioned place preference (Marquez et al., 2008). $\beta$-endorphin binds with high affinity to $\mu$ - and $\delta$-opioid receptors, while its affinity to the $\mathrm{K}$-opioid receptor is lower (Akil et al., 1984).

Using opioid receptor antagonists, several studies support a role for the $\mu$-opioid type receptor in cocaine addiction in humans (Ghitza et al., 2010) and animal models (Kreek et al., 2009; Simmons and Self, 2009). Some studies showed that extended access to cocaine self-administration was associated with increased activity of the $\kappa$-opioid system or its endogenous agonist, dynorphin, in rats (Wee and Koob, 2010). K-opioid receptor activation decreases acquisition or maintenance of cocaine, ethanol, morphine, and heroin by lowering their reinforcing/rewarding effects (Xi et al., 1998; Logrip et al., 2008; Wee et al., 2009). However, during lower sub-threshold doses of cocaine and morphine during maintenance, or abstinence following long access to cocaine, $\kappa$-opioid receptor activation facilitates substance self-administration or reinstatement, possibly through aversivelike and stress-like effects (Kuzmin et al., 1997; Wee and Koob, 2010). There is also some evidence for the involvement of the $\delta$-opioid receptor in reward and addiction, but the studies are equivocal. Some have shown that non-peptidic $\delta$-opioid receptor agonists elicit reward (Longoni et al., 1998), but some reported negligible abuse-related effects (Negus et al., 1998). The selective $\delta$-opioid receptor antagonist naltrindole decreased responding for cocaine in rats, regardless of the schedule of reinforcement (Reid et al., 1995). Conversely, others (de Vries et al., 1995) reported that only a high dose of naltrindole, which decreased locomotor activity, attenuated cocaine selfadministration. Intra-accumbal infusion of this $\delta$-opioid receptor antagonist decreased cocaine self-administration, while administration into the VTA significantly increased cocaine-maintained responding (Ward and Roberts, 2007). Some demonstrated that withdrawal from cocaine, resulted in increased anxiety and depression, accompanied the desensitization of $\delta$-opioid receptor function. Furthermore, cocaine-induced anxiety- and depressive-like behaviors were reversed by the $\delta$-opioid receptor agonist SNC80 (Perrine et al., 2008).

Previous studies reported an attenuated $\beta$-endorphin response during ethanol or nicotine relapse. One study examined the extent to which $\beta$-endorphin response to stress is associated with early smoking relapse. The authors found that smokers who relapsed exhibited attenuated $\beta$-endorphin response to stressors, compared to those who maintained abstinence over the same period (Shaw and al'Absi, 2008). Moreover, smokers who underwent weekly exercise sessions had higher $\beta$-endorphin plasma levels and demonstrated a reduced smoking rate (Leelarungrayub et al., 2010). In another study, withdrawal from ethanol consumption led to decreased $\beta$-endorphin plasma levels. Chronic treatment with acamprosate, which increases $\beta$-endorphin plasma concentrations, caused a significant reduction in ethanol intake (Zalewska-Kaszubska et al., 2008).

Preliminary results elucidate a novel role for $\beta$-endorphin in incubation of cocaine craving, a model that evaluates abuserelated drug effects a long time after forced abstinence (Figure 1A). During the satiated state, $\beta$-endorphin levels correspond to substance self-administration. Associated cues throughout short-term withdrawal trigger elevated $\beta$-endorphin release (Roth-Deri et al., 2008). Throughout longterm abstinence, cues are unable to elicit enough $\beta$-endorphin release, concurrently with drug craving. Interestingly exogenous $\beta$-endorphin negated the heightened craving during long-term abstinence by acting on the $\delta$-opioid-like receptor (unpublished results). Therefore, restoring abstinenceinduced deficits in $\beta$-endorphin levels may be an important factor in preventing craving and maintaining abstinence.

We suggest that anxious-like and impulsive responses are linked to the compulsive seeking behavior observed after abstinence from substance abuse, through the $\delta$-opioid receptor. By applying $\delta$-opioid receptor agonists, we may bypass the lower efficacy of opioid-like receptor activity in the abstinence phase. Accordingly, this could cause a decrease in craving, simultaneously with decreased anxiety-like and depressive-like behaviors during extinction response.

Another candidate for intervention in substance abuse and relapse is DHEA, a natural steroid produced from cholesterol by the adrenal glands. DHEA is also produced in the gonads, adipose tissue, and the brain. It is structurally similar to, and is a precursor of, androstenedione, testosterone, and estrogens (Yadid et al., 2010).

Studies indicate that DHEA administration improves memory and cognitive processing; acts as a growth hormone in helping neurons grow new dendrites and controls levels of the stress hormone cortisol (Flood et al., 1988; Ulmann et al., 2009; Yadid et al., 2010). In healthy men and women, it was found that DHEA supplementation improved mood and sense of well being, including better quality of sleep, increased energy, relaxation, and higher capability of handling stress (Morales et al., 1994). Longterm treatment has been shown to modulate 


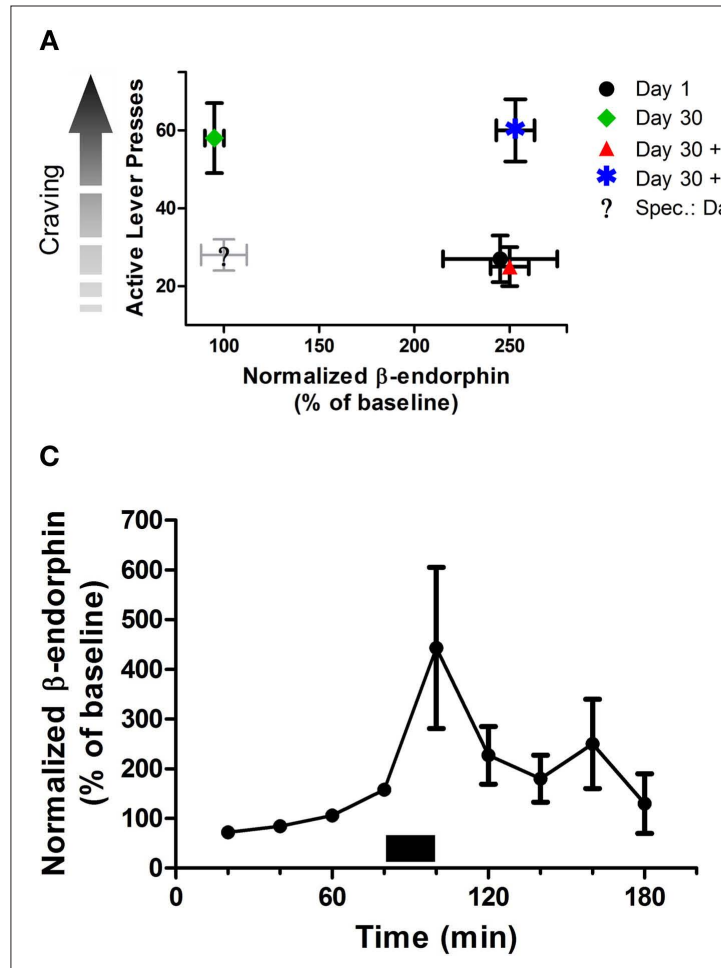

FIGURE 1 | Stress and mood in relation to substance addiction. (A) $\beta$-endorphin levels are inversely correlated with craving during prolonged abstinence. Rats were trained to self administer cocaine $(0.75 \mathrm{mg} / \mathrm{kg} / \mathrm{infusion}$; $6 \mathrm{~h} /$ day; 10 days). Cocaine craving was measured by the number of active lever presses. $\beta$-endorphin levels were measured in the extracellular space of the $n$. accumbens, using the microdialysis technique. Craving was examined on day 1 or on day 30 of forced abstinence. Heightened craving is correlated with low $\beta$-endorphin release or low activity of the $\delta$-opioid receptor in the $n$. accumbens. On withdrawal day 1 (black dot), $\beta$-endorphin levels are high and craving is low. On withdrawal day 30 (green rhomb), $\beta$-endorphin levels are low and craving is high. Adding $\beta$-endorphin (red triangle) markedly reduces craving, while a $\delta$-opioid receptor antagonist (blue star) prevents the $\beta$-endorphin effect. Administrating a $\delta$-opioid receptor agonist alone at 30 -day abstinence is also expected to markedly reduce craving (legend: "Spec."). Note: $\beta$-E, $\beta$-endorphin; $\delta$-Ant, $\delta$-opioid antagonist; $\delta$-Ago., $\delta$-opioid agonist.
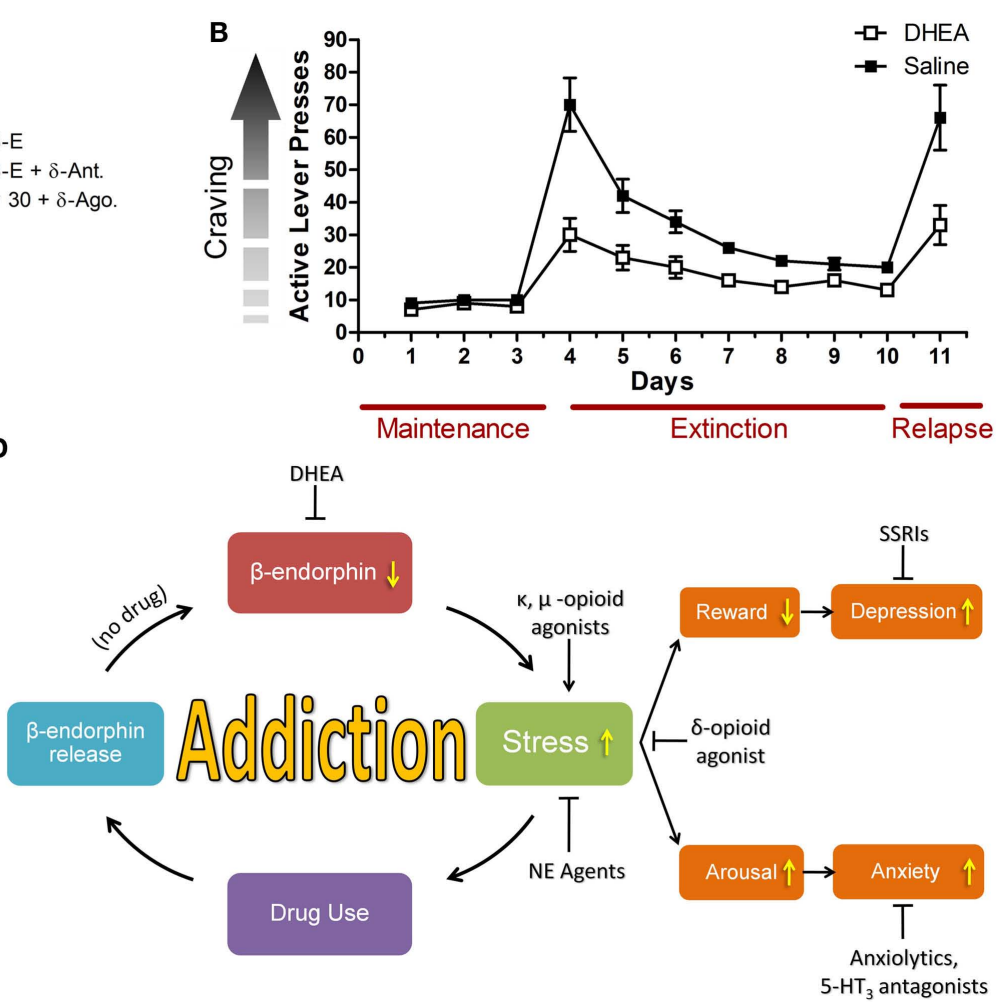

(B) Effect of DHEA treatment or saline on extinction of cocaine selfadministration. Rats were trained to self administer cocaine $(1.5 \mathrm{mg} / \mathrm{kg} /$ infusion), after reaching stable maintenance, rats were either injected with DHEA or saline 90 min prior to placement in the operant chambers. After reaching abstinence, rats were reinstated with $10 \mathrm{mg} / \mathrm{kg}$ i.p. cocaine. DHEA significantly facilitates withdrawal and attenuates drug-induced relapse. (C) DHEA and $\beta$-endorphin are linked together. Using the reverse microdialysis technique, DHEA-sulfate (30 nM, marked by a bar) was applied into the $\mathrm{n}$. accumbens, and $\beta$-endorphin levels in dialysates were measured. Perfusion of DHEA-sulfate causes a significant in situ transient increase in $\beta$-endorphin release. (D) A flow chart summarizing the role of stress and mood states in addiction. Note: stress is a core reinforcing component in addiction, and a major modulator of mood states. Hence, stress modulators that secondarily affect mood, strongly oppose relapse to substance usage. NE, norepinephrine; SSRIs, selective serotonin reuptake inhibitors. distress, improve mood, and relieve depressive-like symptoms (Wolkowitz and Reus, 1999).

Recently it was successfully shown in an animal model of addiction that chronic exposure to exogenous DHEA markedly attenuated cocaine self-administration and decreased cocaine-seeking behavior of rats when applied during cocaine intake (Doron et al., 2006a) or during abstinence (Figure 1B). In another two preclinical studies it was found that DHEA attenuated reinstatement of cocaine-seeking behavior in rats (Doron et al., 2006b; Malkesman et al., 2006) and significantly increased neurogenesis (generation of newly formed neurons;
Charalampopoulos et al., 2008; Yadid et al., 2010). In addition, the effect of DHEA was mimicked in heroin addicted rats (unpublished data) and humans (Maayan et al., 2008).

Interestingly, DHEA and $\beta$-endorphin are linked together. Application of exogenous DHEA-S (phosphorylated DHEA) into the NAc increases extracellular levels of $\beta$-endorphin (Figure 1C). Therefore, a lingering decease in brain DHEA supply may decrease extracellular $\beta$-endorphin levels, and this may signal lower capacity to cope with mood fluctuations and stress, that accompany the increase of substance craving.
These suggested candidates may represent a hallmark of drug abstinence and an adaptive mechanism in coping with a history of substance abuse disorders (Figure 1D). Prospective prolongation of DHEA and $\beta$-endorphin function may result in protracted drug withdrawal.

\section{REFERENCES}

Akil, H., Watson, S. J., Young, E., Lewis, M. E., Khachaturian, H., and Walker, J. M. (1984). Endogenous opioids: biology and function. Аnпu. Rev. Neurosci. 7, 223-255.

Belujon, P., and Grace, A. A. (2011). Hippocampus, amygdala, and stress: interacting systems that affect susceptibility to addiction. Ann. N. Y. Acad. Sci. 1216, 114-121. 
Boutrel, B., and de Lecea, L. (2008). Addiction and arousal: the hypocretin connection. Physiol. Behav. 93, 947-951.

Bruchas, M. R., Land, B. B., and Chavkin, C. (2010). The dynorphin/kappa opioid system as a modulator of stress-induced and pro-addictive behaviors. Brain Res. 1314, 44-55.

Bruijnzeel, A.W. (2012). Tobacco addiction and the dysregulation of brain stress systems. Neurosci. Biobehav. Rev. 36, 1418-1441.

Charalampopoulos, I., Remboutsika, E., Margioris, A. N., and Gravanis, A. (2008). Neurosteroids as modulators of neurogenesis and neuronal survival. Trends Endocrinol. Metab. 19, 300-307.

Costall, B., and Naylor, R. J. (1992). Anxiolytic potential of 5-HT3 receptor antagonists. Pharmacol. Toxicol. 70, 157-162.

de Lecea, L., Carter, M. E., and Adamantidis, A. (2012). Shining light on wakefulness and arousal. Biol. Psychiatry 71, 1046-1052.

de Oliveira Citó Mdo, C., da Silva, F. C., Silva, M. I., Moura, B. A., Macêdo, D. S., Woods, D. J., Fonteles, M. M., Vasconcelos, S. M., and Sousa, F. C. (2012). Reversal of cocaine withdrawal-induced anxiety by ondansetron, buspirone and propranolol. Behav. Brain Res. 231, 116-123.

de Vries, T. J., Babovic-Vuksanovic, D., Elmer, G., and Shippenberg, T. S. (1995). Lack of involvement of delta-opioid receptors in mediating the rewarding effects of cocaine. Psychopharmacology (Berl.) 120, 442-448.

Doron, R., Fridman, L., Gispan-Herman, I., Maayan, R., Weizman, A., and Yadid, G. (2006a). DHEA, a neurosteroid, decreases cocaine self-administration and reinstatement of cocaine-seeking behavior in rats. Neuropsychopharmacology 31, 2231-2236.

Doron, R., Fridman, L., and Yadid, G. (2006b). Dopamine-2 receptors in the arcuate nucleus modulate cocaine-seeking behavior. Neuroreport 17, 1633-1636.

Flood, J. F., Smith, G. E., and Roberts, E. (1988). Dehydroepiandrosterone and its sulfate enhance memory retention in mice. Brain Res. 447, 269-278.

Froeliger, B., Modlin, L. A., Kozink, R. V., Wang, L., and McClernon, F. J. (2012). Smoking abstinence and depressive symptoms modulate the executive control system during emotional information processing. Addict. Biol. 17, 668-679.

Garland, E. L., Carter, K., Ropes, K., and Howard, M. O. (2012). Thought suppression, impaired regulation of urges, and addiction-Stroop predict affect-modulated cue-reactivity among alcohol dependent adults. Biol. Psychol. 89, 87-93.

Ghitza, U. E., Preston, K. L., Epstein, D. H., Kuwabara, H., Endres, C. J., Bencherif, B., Boyd, S. J., Copersino, M. L., Frost, J. J., and Gorelick, D. A. (2010). Brain mu-opioid receptor binding predicts treatment outcome in cocaine-abusing outpatients. Biol. Psychiatry 68, 697-703.

Kalivas, P.W., and Volkow, N. D. (2005). The neural basis of addiction: a pathology of motivation and choice. Am. J. Psychiatry 162, 1403-1413.

Kirby, L. G., Zeeb, F. D., and Winstanley, C. A. (2011). Contributions of serotonin in addiction vulnerability. Neuropharmacology 61, 421-432.

Koob, G. F., and Zorrilla, E. P. (2010). Neurobiological mechanisms of addiction: focus on corticotropinreleasing factor. Curr. Opin. Investig. Drugs 11, 63-71.
Kreek, M. J., Zhou, Y., Butelman, E. R., and Levran, O. (2009). Opiate and cocaine addiction: from bench to clinic and back to the bench. Curr. Opin. Pharmacol. 9, 74-80.

Kuzmin, A. V., Semenova, S., Gerrits, M. A., Zvartau, E. E., and Van Ree, J. M. (1997). Kappa-opioid receptor agonist U50,488 $\mathrm{H}$ modulates cocaine and morphine self-administration in drug-naive rats and mice. Eur. J. Pharmacol. 321, 265-271.

Le Merrer, J., Befort, K., Gardon, O., Filliol, D., Darcq, E., Dembele, D., Becker, J. A., and Kieffer, B. L. (2012). Protracted abstinence from distinct drugs of abuse shows regulation of a common gene network. Addict. Biol. 17, 1-12.

Leelarungrayub, D., Pratanaphon, S., Pothongsunun, P., Sriboonreung, T., Yankai, A., and Bloomer, R. J. (2010). Vernonia cinerea Less. supplementation and strenuous exercise reduce smoking rate: relation to oxidative stress status and beta-endorphin release in active smokers. J. Int. Soc. Sports Nutr. 7, 21.

Li, Y. Q., Li, F. Q., Wang, X. Y., Wu, P., Zhao, M., Xu, C. M., Shaham, Y., and Lu, L. (2008). Central amygdala extracellular signal-regulated kinase signaling pathway is critical to incubation of opiate craving. J. Neurosci. 28, 13248-13257.

Logrip, M. L., Janak, P. H., and Ron, D. (2008). Dynorphin is a downstream effector of striatal BDNF regulation of ethanol intake. FASEB J. 22, 2393-2404.

Longoni, R., Cadoni, C., Mulas, A., Di Chiara, G., and Spina, L. (1998). Dopamine-dependent behavioural stimulation by non-peptide delta opioids BW373U86 and SNC 80: 2. Place-preference and brain microdialysis studies in rats. Behav. Pharmacol. 9, 9-14.

Lu, L., Shepard, J. D., Hall, F. S., and Shaham, Y. (2003). Effect of environmental stressors on opiate and psychostimulant reinforcement, reinstatement and discrimination in rats: a review. Neurosci. Biobehav. Rev. 27, 457-491.

Maayan, R., Touati-Werner, D., Shamir, D., Yadid, G., Friedman, A., Eisner, D., Weizman, A., and Herman, I. (2008). The effect of DHEA complementary treatment on heroin addicts participating in a rehabilitation program: a preliminary study. Eur. Neuropsychopharmacol. 18, 406-413.

Malkesman, O., Braw, Y., Maayan, R., Weizman, A., Overstreet, D. H., Shabat-Simon, M., Kesner, Y., Touati-Werner, D., Yadid, G., and Weller, A. (2006). Two different putative genetic animal models of childhood depression. Biol. Psychiatry 59, 17-23.

Marquez, P., Baliram, R., Dabaja, I., Gajawada, N., and Lutfy, K. (2008). The role of beta-endorphin in the acute motor stimulatory and rewarding actions of cocaine in mice. Psychopharmacology (Berl.) 197, 443-448.

Merenlender-Wagner, A., Dikshtein, Y., and Yadid, G. (2009). The beta-endorphin role in stress-related psychiatric disorders. Curr. Drug Targets 10, 1096-1108.

Moeller, F. G. (2012). Sex, stress, and drug cues in addiction. Am. J. Psychiatry 169, 351-353.

Morales, A. J., Nolan, J. J., Nelson, J. C., and Yen, S. S. (1994). Effects of replacement dose of dehydroepiandrosterone in men and women of advancing age. J. Clin. Endocrinol. Metab. 78, 1360-1367.

Negus, S. S., Gatch, M. B., Mello, N. K., Zhang, X., and Rice, K. (1998). Behavioral effects of the delta-selective opioid agonist SNC80 and related compounds in rhesus monkeys. J. Pharmacol. Exp. Ther. 286, 362-375.
Nestler, E. J. (2005). Is there a common molecular pathway for addiction? Nat. Neurosci. 8, 1445-1449.

Packard, M. G. (2009). Anxiety, cognition, and habit: a multiple memory systems perspective. Brain Res. 1293, 121-128.

Pani, P. P., Trogu, E., Vecchi, S., and Amato, L. (2011). Antidepressants for cocaine dependence and problematic cocaine use. Cochrane Database Syst. Rev. 12, CD002950.

Perrine, S.A., Sheikh, I. S., Nwaneshiudu, C.A., Schroeder, J. A., and Unterwald, E. M. (2008). Withdrawal from chronic administration of cocaine decreases delta opioid receptor signaling and increases anxiety- and depression-like behaviors in the rat. Neuropharmacology 54, 355-364.

Reid, L. D., Glick, S. D., Menkens, K. A., French, E. D., Bilsky, E. J., and Porreca, F. (1995). Cocaine selfadministration and naltrindole, a delta-selective opioid antagonist. Neuroreport 6, 1409-1412.

Roth-Deri, I., Green-Sadan, T., and Yadid, G. (2008). Betaendorphin and drug-induced reward and reinforcement. Prog. Neurobiol. 86, 1-21.

Rounsaville, B. J. (2004). Treatment of cocaine dependence and depression. Biol. Psychiatry 56, 803-809.

Shaw, D., and al'Absi, M. (2008). Attenuated beta endorphin response to acute stress is associated with smoking relapse. Pharmacol. Biochem. Behav. 90, 357-362.

Simmons, D., and Self, D. W. (2009). Role of mu- and delta-opioid receptors in the nucleus accumbens in cocaine-seeking behavior. Neuropsychopharmacology 34, 1946-1957.

Sinha, R. (2011). New findings on biological factors predicting addiction relapse vulnerability. Curr. Psychiatry Rep. 13, 398-405.

Stulz, N., Thase, M. E., Gallop, R., and Crits-Christoph, P. (2011). Psychosocial treatments for cocaine dependence: the role of depressive symptoms. Drug Alcohol Depend. 114, 41-48.

Tang, X. C., McFarland, K., Cagle, S., and Kalivas, P. W. (2005). Cocaine-induced reinstatement requires endogenous stimulation of mu-opioid receptors in the ventral pallidum. J. Neurosci. 25, 4512-4520.

Ulmann, L., Rodeau, J. L., Danoux, L., ContetAudonneau, J. L., Pauly, G., and Schlichter, R. (2009). Dehydroepiandrosterone and neurotrophins favor axonal growth in a sensory neuron-keratinocyte coculture model. Neuroscience 159, 514-525.

Ward, S. J., and Roberts, D. C. (2007). Microinjection of the delta-opioid receptor selective antagonist naltrindole 5 -isothiocyanate site specifically affects cocaine self-administration in rats responding under a progressive ratio schedule of reinforcement. Behav. Brain Res. 182, 140-144.

Wee, S., and Koob, G. F. (2010). The role of the dynorphin-kappa opioid system in the reinforcing effects of drugs of abuse. Psychopharmacology (Berl.) 210, 121-135.

Wee, S., Orio, L., Ghirmai, S., Cashman, J. R., and Koob, G. F. (2009). Inhibition of kappa opioid receptors attenuated increased cocaine intake in rats with extended access to cocaine. Psychopharmacology (Berl.) 205, 565-575.

Weiss, F., Ciccocioppo, R., Parsons, L. H., Katner, S., Liu, X., Zorrilla, E. P., Valdez, G. R., Ben-Shahar, O., Angeletti, S., and Richter, R. R. (2001). Compulsive drug-seeking behavior and relapse. Neuroadaptation, stress, and conditioning factors. Ann. N. Y. Acad. Sci. 937, 1-26. 
Wolkowitz, O. M., and Reus, V. I. (1999). Treatment of depression with antiglucocorticoid drugs. Psychosom. Med. 61, 698-711.

Xi, Z. X., Fuller, S. A., and Stein, E. A. (1998). Dopamine release in the nucleus accumbens during heroin self-administration is modulated by kappa opioid receptors: an in vivo fast-cyclic voltammetry study. J. Pharmacol. Exp. Ther. 284, 151-161.

Yadid, G., Sudai, E., Maayan, R., Gispan, I., and Weizman, A. (2010). The role of dehydroepiandrosterone
(DHEA) in drug-seeking behavior. Neurosci. Biobehav. Rev. 35, 303-314.

Zalewska-Kaszubska, J., Gorska, D., Dyr, W., and Czarnecka, E. (2008). Effect of chronic acamprosate treatment on voluntary alcohol intake and betaendorphin plasma levels in rats selectively bred for high alcohol preference. Neurosci. Lett. 431, 221-225.

Received: 07 May 2012; accepted: 28 June 2012; published online: 23 July 2012.
Citation: Yadid G, Redlus L, Barnea R and Doron R (2012) Modulation of mood states as a major factor in relapse to substance use. Front. Mol. Neurosci. 5:81. doi: 10.3389/ fnmol.2012.00081

Copyright (C) 2012 Yadid, Redlus, Barnea and Doron. This is an open-access article distributed under the terms of the Creative Commons Attribution License, which permits use, distribution and reproduction in other forums, provided the original authors and source are credited and subject to any copyright notices concerning any third-party graphics etc. 